\title{
GLOBALIZAÇÃO E EDUCAÇÃO: DEMONSTRANDO A EXISTÊNCIA DE UMA "CULTURA EDUCACIONAL MUNDIAL COMUM" OU LOCALIZANDO UMA "AGENDA GLOBALMENTE ESTRUTURADA PARA A EDUCAÇÃO”?
}

\author{
Roger DaLE*
}

\begin{abstract}
RESUMO: Este trabalho examina e relação entre globalização e educação. Para o fazer, contrasta duas abordagens dessa relação, uma designada "Cultura Educacional Mundial Comum" que foi desenvolvida ao longo de vários anos pelo professor John Meyer e seus colegas da Universidade de Stanford (Califórnia), outra referida como "Agenda Globalmente Estruturada para a Educação" que é desenvolvida pelo autor deste trabalho. Enquanto a primeira conota uma sociedade, ou política, internacional constituída por Estados-nação individuais autónomos, a segunda implica especialmente forças económicas operando supra e transnacionalmente para romper, ou ultrapassar, as fronteiras nacionais, ao mesmo tempo que reconstróem as relações entre as naçōes. Defende-se que as duas abordagens diferem consideravelmente em cada uma das dimensōes-chave da relação entre globalização e educação. Assim, diferem também na adequação das explicaçōes que propiciam para o fenómeno da globalização.
\end{abstract}

Palavras-chave: Globalização e educação. Cultura universal da educação. Estado nacional e educação.

GLOBALIZATION AND EDUCATION: DEMONSTRATING THE EXISTENCE of a "Global Common Educational Culture" or locating a "Globally Structured Agenda for Education"?

ABSTRACT: This paper explores the relation between globalization and education contrasting two approaches: one, called the "Global Common Educational Culture" that was developed during twenty

Tradução de António M. Magalhães, com revisão científica de Stephen R. Stoer e António M. Magalhães da FPCE-UP (Portugal). Texto publicado originalmente na revista Educação, Sociedade \& Culturas (Porto, n. 16, 2001, p. 133-169). Reprodução gentilmente autorizada pelo editor, Stephen R. Stoer.

** Faculdade de Educação, Universidade de Auckland. E-mail: r.dale@bristol.ac.uk

Educ. Soc., Campinas, vol. 25, n. 87, p. 423-460, maio/ago. 2004

Disponível em <http://www.cedes.unicamp.br> 
years by Professor John Meyer and his colleagues from the University of Stanford (California), the other referred to as a "Globally structured agenda for education", developed by the present author. Whereas the first one connotes an international society or policy constituted by individual, autonomous Nation-States, the second one implies more particularly economical forces operating supra- and trans-nationally to break or exceed national borders, while reconstructing relations among States. We advocate that both approaches considerably differ in each key-dimension of the relationship between globalization and education. They thus differ when appropriating their explanations of the globalization phenomena.

Keywords: Globalization and Education. Universal Culture of Education. National States and Education.

\section{Introdução}

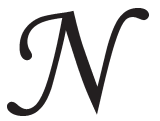

os últimos anos, entre os investigadores dos diferentes tipos de instituições sociais, tem surgido uma considerável quantidade de especulações e profecias, dúvidas e medos, saliência e celebração em volta da "globalização" e das suas consequências; fenómeno este a que a educação não tem permanecido imune. $\mathrm{O}$ estatuto da globalização nestes debates é o de frequentemente ou surgir como uma resposta para todos os tipos de questōes levantadas pelas mudanças manifestas e palpáveis experienciadas pelas sociedades ocidentais contemporâneas, ou como um inevitável destino, meta ou telos. Estes debates, contudo, têm sido de algum modo confusos e muito pouco informados. A "globalização" é frequentemente considerada como representando um inelutável progresso no sentido da homogeneidade cultural, como um conjunto de forças que estão a tornar os estados-nação obsoletos e que pode resultar em algo parecido com uma política mundial, e como reflectindo o crescimento irresistível da tecnologia da informação. Menos comuns do que essas aplicaçóes indiscriminadas do termo, ou do que o seu uso promíscuo como rótulo para todos os tipos de fenómenos, têm sido as tentativas para confrontar teoricamente a natureza e os efeitos da composição e das consequencias da mutação das forças supranacionais, que não pretendem a priori nem substituir o estado para fazer o mundo mais homogéneo, nem ser guiadas pelas cegas forças tecnológicas.

Ao examinar a relação entre globalização e educação tentarei esclarecer as implicações deste tipo de análise teórica. Partirei da 
afirfmação de que a globalização, na medida em que pode afectar as políticas e as práticas educativas nacionais, implica a apreciação da natureza e da força do efeito extra nacional, o que é que pode ser afectado e como é que esse efeito acontece. Isto poderá parecer óbvio, mas em muitas análises da relação entre globalização e educação essa mesma relação é reduzida ao correlato entre uma (vaga) globalização e, no mínimo, reformas similares ao nível da educação em diferentes países, como a acção do mercado ou a "devolução". Eu sugiro que uma teoria efectiva dos efeitos da globalização sobre a educação precisa de (a) especificar a natureza da globalização, (b) indicar claramente o que é que se quer dizer com "educação" e (c) especificar como é que a globalização afecta a educação, quer directamente, de forma identificável, e indirectamente, quer, e por consequencia, especificando outras mudanças que possa trazer no seu próprio interior ou no sector da educação.

A forma como pretendo proceder é através do contraste entre duas abordagens da questão da relação entre globalização e educação que não são vulneráveis à crítica esboçada anteriormente, na medida em que contêm todos os três elementos que eu proponho como essenciais para uma efectiva teoria do efeito da globalização sobre a educação. Contudo, enquanto estes quadros metateóricos de compreensão são necessários para uma teoria efectiva da globalização, não apontam inevitavelmente nas mesmas direcções explicativas. De facto, e como se tornará evidente, as duas abordagens diferem consideravelmente em cada uma das dimensões-chave da relação entre globalização e educação. E, consequentemente, como argumentarei, diferem na adequação das explicações que propiciam.

\section{A abordagem CEMC}

A primeira abordagem que discutirei é uma teoria muito bem estabelecida sobre o efeito da globalização sobre a .educação. Foi desenvolvida já há uns anos por John Meyer, seus colegas e estudantes em Stanford. Referirei essa abordagem sob a desigãção "Cultura Educacional Mundial Comum” (daqui em diante CEMC). No essencial, os proponentes desta perspectiva defendem que o desenvolvimento dos sistemas educativos nacionais e as categorias curriculares se explicam através de modelos universais de educação, de estado e de sociedade, mais do que através de factores nacionais distintivos. A outra aborda- 
gem, que eu próprio pretendo desenvolver, ${ }^{1}$ será referida como "Agenda Global Estruturada para a Educação" (AGEE). Baseia-se em trabalhos recentes sobre economia política internacional (por exemplo, Cox, 1996; Mittelman, 1996; Hettne, 1996) que encaram a mudança de natureza da economia capitalista mundial como a força directora da globalização e procuram estabelecer o seus efeitos, ainda que intensamente mediados pelo local, sobre os sistemas educativos.

A comparação pode começar, com toda a utilidade, com as próprias designações. Tanto "Mundial" como "Global" implicam um foco extra nacional. A principal diferença relevante entre elas é que a primeira conota uma sociedade, ou política, internacional constituída por estadosnação individuais atónomos; o que se pressupõe é essencialmente uma comunidade internacional. "Global", pelo contrário, implica especialmente forças económicas operando supra e transnacionalmente para romper, ou ultrapassar, as fronteiras nacionais, ao mesmo tempo que reconstróem as relações entre as nações. "Agenda Estruturada" contrasta com "Cultura"; esta implica a partilha - e o ser igualmente acessível de um conjunto de recursos a um alto nível de generalidade; aquela, um conjunto sistemático de perguntas incontornáveis para os estados-nação, enquadradas pela relação destes com a globalização. E, como pormenorizarei adiante, embora o termo seja comum, a "educação" é concebida de forma muito diferente nas duas abordagens.

\section{Uma cultura universal de educação}

CEMC é uma designação apropriada para este tipo de trabalho, dado que é precisamente aquilo que em essência necessita de ser estabelecido e demonstrado. O trabalho tem sido desenvolivdo nos últimos 20 anos através de um amplo leque de publicações de um grupo de investigadores que poderiam ser referidos como "institucionalistas mundiais", na medida em que o seu trabalh o desenvolve numa escala mundial alguns dos pressupostos doutrinários daquilo que se tornou conhecido como institucionalismo sociológico (ver Powell \& DiMaggio, 1993; Finnemore, 1996a; Hall \& Taylor, 1996). O argumento central dos institucionalistas mundiais é que as instituições do estado-nação, e o próprio estado, devem ser vistos como sendo essencialmente moldados a um nível supranacional através de uma ideologia do mundo dominante (ou Ocidente), e não como criações nacionais autónomas e 
únicas. Sob esta perspectiva, os estados têm a sua actividade e as suas políticas moldadas por normas e cultura universais.

O cerne desta importante, audaciosa e ambiciosa tese é mais sociológico do que educacional, embora os estudiosos da educação não deixem de beneficiar com aquilo que actualmente se apresenta, depois de 20 anos de desenvolvimento, como uma impressionantemente coerente e consistente abordagem ao nível macro de explicação. Não teve grandes modificações durante aquele período [embora seja possível discernir algumas derivas potenciais numa recente e importante apresentação da abordagem (ver Meyer et al., 1997)]. Embora a teoria sobre a qual a CEMC repousa tenha sido testada em alguns campos sociais, a maior demonstração da teoria dos institucionalistas mundiais pode ser encontrada no campo da educação, tanto na massiva e rápida expansão dos sistemas de educação nacionais como no inesperado isomorfismo global das categorias curriculares em todo o mundo; este isomorfismo acontece independentemente das dfierenças nacionais ao nível económico, político e cultural. A teoria é densa e complexa e é difícil fazer-lhe total justiça aqui. Talvez a melhor forma de começar seja com o esclarecimento da sua teoria básica, dado que tal permitirá demonstrar o seu âmbito e a sua ambição assim como indicar o lugar da educação no seu interior. Este esclarecimento poderá ser encontrado no artigo de Meyer, Boli \& Thomas, intitulado "Ontology and rationalization in the western cultural account” (1987), que constitui o capítulo principal no conjunto de trabalhos teóricos mais significativos da abordagem dos institucionalistas mundiais. Estes autores argumentam que:

As instituições ao construírem, e ao darem sentido a, entidades sociais modernas e sua acção racionalizada têm um carácter muito mais amplo e universal do que qualquer realização que possam constituir (...) em dois sentidos relacionados entre si. Primeiro, estas instituiçōes incorporam reivindicações universalizadas ligadas a leis da natureza e de tipo moral. A acção económica, educacional ou política é legitimada em termos de afirmaçôes muito gerais acerca do progresso, justiça e de ordem natural (...). As diferenças que sobrevêm no interior das realizaçôes locais são limitadas e permanecem no âmbito do contexto do quadro cultural mais amplo. Por exemplo, os professores adoptam diferentes estilos, diferentes tipos de técnicas de gestão das organizações, e afirmam os diferentes regimes de instâncias ideológicas tudo dentro da ordem constitutiva daquilo que significa ser um professor, uma organização de negócios e um estado-nação (...). Segundo, reivindicações e definiçôes institucionais específicas tendem na prática a ser muito se- 
Globalização e educação: demonstrando a existência de uma...

melhantes em quase todos os lugares. Diferenças entre as várias realizaçōes particulares resultam da organização dessa realização a partir da ênfase variável ou das interpretações de regras institucionais mais gerais (...). Não se deve ver estas instituições em toda a sua diversidade apenas como construções da experiência humana em contextos locais, mas como algo que se desenvolve a partir de uma cultura histórica universalística dominante (...). Assim, nos sistemas sociais modernos, é profícuo ver a estrutura social não como a reunião de padrōes de interacção local, mas como edifícios ideológicos de elementos institucionalizados que substanciam a sua autoridade em regras e concepçōes mais universais. As estruturas formais da sociedade, desde a definição e propriedades do individual até à forma e ao conteúdo de organizaçôes como as escolas, as empresas, os movimentos sociais e os estados, derivam ou são ajustadas para se adequarem às regras muito gerais que possuem pelo mundo fora significado e poder. (Meyer et al., 1997, p. 27-29; sublinhado no original)

As instituições poder ser vistas como “'instâncias culturais’ sob cuja autoridade a acção ocorre e as unidades sociais justificam a sua existência” (ibid., p. 29). O conteúdo dessas instâncias funda-se nas características gerais da instância cultural do Ocidente que enfatiza a racionalidade, o progresso, o individualismo e a justiça. Meyer, Boli \& Thomas centram-se em quatro consequências dessa instância cultural.

Primeiro, a racionalização (...) conduz à formação de uma gama extraordinária de actores legitimados e reificados enquanto seres racionais e com intençôes - indivíduos, associaçōes, classes, organizaçōes, grupos étnicos, estados-nação. Segundo, os actores colectivos possuem maior legitimidade e autoridade se estiverem fundados numa teoria da pertença individual e da actividade, como o estado-nação ou a empresa racionalizada. Terceiro, as entidades organizacionais ligadas às teorias da justiça e do progresso ganham especial saliência sobre todas as outras - o indivíduo e o estado-nação são as mais reais de todas (...), variando o equilíbrio entre os dois de uma sociedade para outra (...). Quarto, na medida em que derivam da ideologia cultural universalística, as formas culturais dominantes, incluindo a estrutura e as fronteiras da acção colectiva, estão relativamente padronizadas entre as sociedades. Há apenas uma relação livre entre as formas organizacionais e as necessidades práticas e objectivos operando em situaçôes locais. Neste sentido, as estruturas organizacionais ocidentais devem ser vistas mais como actualizaçôes rituais de prescriçôes culturais de base ampla do que como respostas racionais a problemas concretos. (ibid., p. 32; sublinhado meu)

Strang \& Chang resumem a perspectiva de base de uma forma muito clara, significativamente, num artigo sobre a Organização Internacional do Trabalho (OIT): "[este trabalho] vê as estruturas estatais e 
as políticas como sendo informadas pelo projeto cultural do Ocidente no sentido da racionalização do mundo social e da expansão das competências e direitos do indivíduo (...). Centra-se nos produtos; covencionalmente num mapeamento das construçóes nacionais num nível nacional. O seu propósito é o de explorar se os estados actuam como se fossem fortemente penetrados por uma teoria comum do progresso e do valor" (1993, p. 237; grifo no original). Para a educação esta abordagem sublinha que, longe de serem autonomamente construídas a um nível nacional, as políticas nacionais são em essência pouco mais do que interpretações de versões ou guiões que são informados por, e recebem a sua legitimação de, ideologias, valores e culturas de nível mundial.

Das mais acessíveis e relevantes aplicações ${ }^{2}$ deste trabalho em educação são as publicações The political construction of educational expansion (Fuller \& Rubinson, 1992), na qual a questão central é o explicar a expansão dos sistemas educativos, e School knowledge for the masses (Meyer et al., 1992), cuja questão central é a surpreendente homogeneidade das categorias curriculares pelo mundo fora, e a partir da qual retirarei a maior parte dos meus exemplos, na medida em que representa a mais forte defesa da perspectiva CEMC. A questão e o argumento principais são que os trabalhos "convencionais" sobre o crescimento dos sistemas educativos, e das categorias curriculares que eles empregam, que se baseiam em explicações através das tradições educacionais ou necessidades económicas nacionais, não são tão eficazes como aquelas que vêm estas mudanças como fazendo parte da expansão global da cultura mundial baseada nos valores ocidentais de racionalidade e individualidade. De uma perspectiva institucionalista mundial, Ramirez \& Ventrasca (1992) defendem que "a escola de massas não emerge e se desenvolve como função de características societais endógenas, tais como a urbanização ou a industrialização, a estrutura de classes ou o carácter das elites políticas ou religiosas”, antes

desenvolveu-se e expandiu-se como um crescentemente familiar conjunto de configurações ideológicas e organizacionais. Ao longo do tempo histórico e através de diversos projectos, as características da escola moderna de massas tornaram-se num modelo normativo institucional (que) se foi crescentemente ligando ao ascendente estado-nação (que foi) ele próprio inspirado por uma cultura política emergente das dinâmicas conflitantes da economia capitalista mundial (...). A escola de massas tornou-se o conjunto central de actividades 
Globalização e educação: demonstrando a existência de uma...

através do qual as ligações recíprocas entre os indivíduos e estados-nação são forjadas. (ibid., p. 49-50)

As provas empíricas da tese para a CEMC são mais fortes no âmbito que abrangem do que em profundidade. Como dizem Meyer et al., "os nossos dados são forçosamente limitados ou superficiais (...) mas permitem uma avaliação do nível e da difusão dos tópicos curriculares gerais pelos diferentes países ao longo de vastos períodos de tempo" (1992, p. xi-xii). Para os objectivos deste artigo esta afirmação é adequada e apenas uma breve exposição da metodologia será adiantada. $\mathrm{O}$ caso empírico baseia-se numa extensa base de dados que é, em grande parte, feita de afirmações de currículos nacionais colhidas ao longo do tempo e em diversos países. Este material foi usado para construir os indicadores de organização curricular, a data da emergência e a taxa de expansão dos temas, e o tempo dedicado a cada um dos temas. Os dados foram coligidos a partir de fontes históricas nacionais e internacionais publicadas, de respostas a um questionário enviado pelo Gabinete Internacional da Educação para todos os estados-membros da UNESCO em 1984, e de um inquérito feito pela equipa a ministros da educação nacional em 1985. Existe, é claro, uma real possibilidade de ventriloquismo emergente através dessa metodologia. Os próprios quetionários podem construir as características comuns observadas através do fornecimento de categorias de resposta, que assumem a existência de uma forma ou de outra do fenómeno em questão. Um exemplo relacionado com este pode ser encontrado no estudo de Martha Finnemore (1993) do desenvolvimento das políticas de ciência nacionais na maior parte dos países do mundo, independentemente do seu nível de desenvolvimento. Finnemore defende que efectivamente a UNESCO ensina os países em desenvolvimento que eles necessitam de uma política de ciência; podemos questionarnos até que ponto os questionários das organizações internacionais sobre aspectos da provisão e organização educacionais não possuem um efeito similar.

Um segundo tópico de crítica é a natureza dos dados usados. Esta não é muito importante em si mesma, mas pela natureza das proposições que nela se baseiam. A utilização das respostas ao questionário, os materiais provenientes dos ministérios nacionais [que seria impossível verificar ou validar independentemente, como tem sido 
reclamado pelos especialistas regionais que disseram ter encontrado inúmeros erros nos dados (e.g., Hopman, 1993)] e uma variedade de fontes mais ou menos incomensuráveis têm de colocar limites à força dos argumentos que podem ser construídos com base nestes dados. Particularmente preocupante aqui é a comparação que pode ser feita entre a aparente facilidade com que uma base de dados mundial pode ser construída e as enormes dificuldades que OCDE encontrou ao tentar construir um relativamente limitado conjunto de indicadores educacionais entre os seus relativamente homogéneos membros (ver OECD, 1992). Todavia, não se trata de um óbice fatal e aquela base de dados, com os reconhecidos óbices, pode ser considerada adequada aos objectivos para os quais foi usada.

O padrão dos argumentos usados é muito característico e consistente ao longo das muitas publicações produzidas no âmbito desta abordagem. Essencialmente, esta procede através de um processo de eliminação. ${ }^{3}$ Depois de ter estabelecido empiricamente que existe um elevado nível de isomorfismo ou similaridade de categorias curriculares que podem ser encontradas nos sistemas educativos de estadosnação com diferentes níveis de desenvolvimento e com tradições educacionais muito diferentes, os autores fazem uma breve revisão de outras abordagens que vêm o currículo como sendo conjuntos "nacionalmente padronizados de conhecimento socialmente aprovados que, quando comparados internacionalmente, deverão apresentar uma considerável diversidade" (Benavot et al., 1992, p. 41). Assim, tipicamente, os argumentos funcionalistas, que vêm a educação como respondendo a necessidades nacionais de industrialização e urbanização específicas (e diferentes), e consequentemente diferindo em relação ao nível de desenvolvimento, são apontados como deficientes, na medida em que parece que existe um maior grau de similaridade entre os currículos de todos os países do que seria de esperar. $\mathrm{O}$ alvo seguinte são as abordagens "históricas" do desenvolvimento do currículo que se baseiam em pormenorizados estudos de caso de estados-nação individuais. Estes argumentos defendem o carácter único do currículo, baseado no carácter único das histórias e tradiçôes nacionais. A resposta dos proponentes da CEMC a este tipo de argumentos é suficientemente ampla para mostrar a sua utilidade e importânica mas acaba por falhar o objectivo que persegue acerca da padronização mundial das categorias curriculares. Em particular, este tipo de estudo de casos 
Globalização e educação: demonstrando a existência de uma...

não pode nem individual nem colectivamente explicar a consistência das categorias sobre as quais todos os sistemas parecem derivar; como Benavot et al. dizem, "esta linha (historicista) do argumento tende a deixar em aberto a questão da emergência das próprias categorias globais" (ibid., p. 44).

Contudo, é também importante sublinhar que os proponentes da tese CEMC não vêm qualquer inconsistência necessária entre a sua abordagem e aquelas outras mais centradas no nível nacional, estas últimas focando questões particulares ou a pormenorização dos conteúdos curriculares, e a primeira "na emergência de categorias temáticas muito gerais e explicando a sua localização na política oficial" (ibid., p 45). Isto é importante na medida em que parece esclarecer os limites das pretensões dos defensores da CEMC. Contudo, mesmo se eles frequentemente enfatizam que o seu foco são as categorias curriculares, e nada mais do que isso, tem que ser dito que por vezes na apresentação da sua perspectiva acabam por ir para além disso. Por vezes parece ser uma assunção implícita de que a centração dual na escola de massas e nas categorias curriculares constitui uma abordagem compreensiva da educação. Por exemplo, numa das mais fortes expressões do argumento da CEMC afrima-se que:

(u)ma abordagem baseada nas perspectivas políticas institucional e mundial sugere que as estruturas educativas e o conteúdo curricular são institucionalizados em um nível mundial. De acordo com esta perspectiva, a educação de massas e os currículos da escola de massas estão estritamente ligados aos modelos emergentes de sociedade e de educação que se tornaram relativamente padronizados em nível mundial. Estes modelos padronizados ou ideologias criaram efeitos culturais homogeneizantes que minam o impacto dos factores nacionais e locais ao determinarem a composição do currículo. Esta visão implica que as diferenças nacionais relativamente às prioridades curriculares - por exemplo, a prioridade dada à matemática e às ciências - serão relativamente pequenas e acabarão por se diluir ao longo do tempo. (Kamens \& Benavot, 1992, p. 104; sublinhado meu)

O terceiro aspecto do argumento por eliminação surge através do afastamento de qualquer pretensão de fornecer uma base científica para o currículo e da asserção da partilha de pressupostos acerca do valor da educação. $\mathrm{Na}$ introdução ao School knowledge for the masses, por exemplo, John Meyer afirma que 
os investigadores científicos que estudam (a relação entre currículo e objectivos nacionais) não possuem qualquer conhecimento sistemático que mostre, por exemplo, que a instrução em matemática e ciências facilita o crescimento económico, que a instrução em estudos sociais facilita a integração política, ou que qualquer conteúdo instrucional facilite efectivamente a legitimidade e a dominação por uma elite política (...). (Assim), na prática moderna, a teoria científica penetra no discurso social e até na investigação social - mais como uma questão normativa do que como uma questão técnica. São criadas formas (...) enquanto estas se conformam com os valores definidos na teoria mais do que devido a qualquer evidência dos seus efeitos reais. (1992, p. 8, 21)

Uma consequencia fundamental disto é que as "disputas que se desenvolvem no interior do campo da investigação sobre o currículo são construídas em torno de uma visão claramente partilhada - uma zona de silêncio consensual (...). Os conflitos são acerca de saber se ralmente temos ou não uma boa sociedade, se a educação realmente funciona ou não efecientemente e de uma forma justa, e se trabalha ou não realmente no sentido de promover a justiça social e a eficácia necessárias (...). [Assim] na ausência de conhecimento acerca dos impactos sociais das variações curriculares, e na presença de uma pressão mundial do modelo geral de educação como um veículo na procura do progresso, são produzidos fortes constrangimentos no sentido de uma, pelo menos superficial, padronização" (ibid., p. 22).

Mas ainda fica uma parte crucial do argumento da CEMC por esclarecer, o argumento da universalidade da concepção de educação como um bem geral, mesmo que as suas pretensões funcionalistas/instrumentais estejam longe de serem provadas. Como diz John Meyer,

mesmo que houvesse muita ambiguidade acerca de saber se, sob vário aspectos, a educação de massas é um bem geral, ainda assim seria difícil de explicar por que é que a instituição se tornou tão universal. O que conduz à ideia de que os mesmos processos de dimensão mundial que fizeram as virtudes (e até a necessidade) da educação de massas tão evidentemente universais têm também tendência para padronizar pelo menos as categorias gerais do seu conteúdo. (ibid., p. 9)

As bases da teoria acerca da natureza da educação como um bem geral foram estabelecidas por Meyer \& Kamens: "A educação de massas, no período moderno, não só tem sido altamente valorizada como também tem sido vista como um método científico ou racionalizado 
Globalização e educação: demonstrando a existência de uma...

de produzir progresso social" (ibid., p. 171). Esta ideia tem sido elaborada de uma forma extremamente útil numa vigorosa afirmação da abordagem institucionalista feita por Richard Rubinson \& Irene Browne que vai no sentido de que a educação, enquanto instituição, molda e assume comportamentos particulares e, por isso, cria cidadãos modernos. Estes autores argumentam que:

A escola de massas é a forma simbólica chave de pertença na política moderna. A educação é o mecanismo que constrói indivíduos enquanto cidadãos (a "teoria" da escolarização como uma organização de socialização) e determina as seus legítimos lugares na estrutura social (a "teoria" da escolarização como uma organização de estratificação). A teoria institucional enfatiza que as práticas actuais dentro da escolarização não são o que produz os resultados da socialização e da estatificação; antes pelo contrário, as escolas são organizações rituais que criam um conjunto tomado como certo de crenças sobre o poder da educação. As escolas podem não ser organizações de socialização eficientes, mas a própria educação constitui uma teoria da socialização que explica que a escolarização transforma os indivíduos em cidadãos modernos e em trabalhadores produtivos. As escolas podem não ser organizaçôes eficientes no sentido de alterar os efeitos da origem de classe, mas a própria educação constitui uma teoria de alocação que explica por que é que a escolarização produz uma estrutura de estratificação meritocrática. Consequentemente, a educação é uma instituição crucial, na medida em que legitima quer a estrutura política, quer a estrutura económica, não através da transformação dos indivíduos através da socialização ou alocação, mas através da definição institucional dos produtos da escolarização como cidadãos competentes que ganharam a sua posição no sistema de estratificação. (1994, p. 592)

Portanto, o argumento pode ser resumido da seguinte forma. A rápida expansão dos sistemas educativos nacionais e o evidente, mas surpreendente, grau de homogeneidade curricular que é possível observar entre as sociedades do mundo, independentemente de sua localização, nível de desenvolvimento ou religião ou quaisquer outras tradiçôes, não podem ser explicados pelas teorias funcionais, nacionais, culturais ou racional-instrumentais que têm vindo a dominar o estudo dos sistemas educativos ou dos currículos desde então. Eles derivam, em primeiro lugar, precisamente do modelo "estatista" moderno que a partir de 1945 se expandiu rapidamente. Como diz Wong,

(c)om o fim dos velhos impérios coloniais e a subsequente expansão do sistema do estado-nação, emergiu um novo conceito de construção da socieda- 
de enquanto baseada num modelo racional enfatizando o individualismo económico, politico e cultural. Enquanto esses estados procuram o reconhecimento interno e externo para si mesmos como "estados-nação como deve ser”, eles tendem a seguir o exemplo das, e a incorporá-las, concepções prevalecentes na ordem mundial. (1992, p. 126)

A educação é central para esta missão modernizadora, e a estrutura dos currículos escolares está "extremamente ligada à emergência de modelos de sociedade padronizados e ao crescente domínio de modelos padronizados de educação como um componente desses modelos gerais" (Benavot et al., 1992, p. 41), ao passo que "o currículo escolar é mais uma activação ritual de normas e convençóes educacionais mundiais do que uma escolha de sociedades individuais no sentido de reunir determinadas condições locais. A definição de conhecimento legítimo para ser ensinado nas escolas e a selecção e organização hierárquica desses corpos de conhecimento são assim claramente prescritos 'externamente'. No cerne da prescrição está o discurso 'racional' sobre como é que a socialização de crianças em várias áreas disciplinares está ligada à auto-realização do indivíduo e, em última análise, à construção de uma sociedade ideal. O discurso é altamente padronizado e de carácter universalista" (Cha, 1992, p. 65). Contudo, enquanto que a selecção e a organização do conhecimento escolar são extremamente prescritos, como mostram estas citações, estas prescrições são assumidas voluntariamente.

A abordagem CEMC, portanto, constitui uma forte e coerente teoria da relação entre globalização e educaç ão. Ela especifica a natureza da força supranacional, identifica as motivações para os estados incorporarem características centrais universais do modelo de visão do mundo e aponta para os produtos educativos destes processos.

\section{Uma comparação entre a CEMC e a AGEE}

Depois de ter feito um breve resumo da abordagem CEMC da relação entre globalização e educação, gostaria agora de a contrastar com a abordagem AGEE. Estas abordagens têm um número significativo de semelhanças fundamentais, mas as diferenças entre os seus pressupostos e argumentos são de maior relevância. As duas abordagens partilham a ênfase posta na importância das forças supranacionais, na possibilidade de os objectivos políticos, assim como os processos, po- 
derem ser afectados através de influências externas sobre as políticas educativas nacionais, uma ênfase mais na "capacitação" do que na natureza do "impacto" (ver Streeten, 1995) do efeito de forças supranacionais sobre os sistemas educativos nacionais (algo que as distingue a ambas das abordagens do capital humano) e o reconhecimento de que os quadros interpretativos nacionais são moldados quer supranacionalmente, quer nacionalmente. Contudo, há diferenças cruciais em cada um dos aspectos fundamentais do argumento - a natureza da globalização, a compreensão da educação e a relação entre as duas.

\section{A natureza da globalização}

A diferença fundamental entre as duas abordagens reside na compreensão da natureza do fenómeno global. Para a CEMC, trata-se de um reflexo da cultura occidental, baseada cognitivamente em torno de um conjunto particular devalores que penetram em todas as regiões da vida moderna. Para a AGEE, a globalização é um conjunto de dispositivos político-económicos para a organização da economia global, conduzido pela necessidade de manter o sistema capitalista, mais do que qualquer outro conujnto de valores. A adesão aos seus princípios é veiculada através da pressão económica e da percepção do interesse nacional próprio.

Já esclareci que para os proponentes da CEMC a globalização se refere à presença de um conjunto supranacional de ideias, normas e valores que informam as respostas nacionais para dadas questôes. $\mathrm{Na}$ abordagem AGEE, a globalização é vista como sendo construída através de três conjuntos de actividades relacionadas entre si, económicas, políticas e culturais (ver Cox, 1996; Dale, 1998a). Estes podem ser caracterizados como hiper-liberalismo, governação sem governo e mercadorização e consumismo, respectivamente. Trata-se de um processo complexo e frequentemente contraditório que se centra em torno dos três principais agrupamentos de estados, "Europa, "América” e "Ásia”. As comas implicam que essas regiões são mais construções sociais, especialmente político-económicas, do que geograficamente inclusivas. Possuem diferentes níveis de interacção e integração e podem até certo ponto ser vistas como competindo entre si (ver Dale \& Robertson, 1997; Grieco, 1997; Mittelman, 1996; Katzenstein, 1996; Hettne, 1997). Contudo, os agrupamentos regionais partilham a preocupação 
com o controlo e concordam sobre certas regras do jogo. Competem ferozmente para fazer avançar o conjunto de acordos globais que lhe sejam mais favoráveis, mas reconhecem que, em última análise, dependem da existência de um mundo que seja seguro para o prosseguimento da procura do lucro e não de um mundo que seja seguro para perseguir o seu lucro próprio a expensas de outros.

Esta forma e extensão da globalização é diferente de qualquer outra que tenha acontecido anteriormente; ela torna possível, pela primeira vez, falar de uma economia global que inclui todas as naçóes do mundo. Tal resultou do colapso formal da única alternativa ao capitalismo e da aceleração dos processos no sentido da mercadorização de todas as coisas que se fizeram acompanhar desse colapso. Um segundo factor central é que foi o sistema que triunfou e não uma nova nação hegemónica. Como resultado das ETN (Empresas Transnacionais) e das mudanças técnicas na velocidade de transferências financeiras, a economia global escapa à capacidade de até a mais poderosa das nações a poder controlar (embora tal não signifique, é claro, que os EUA não sejam ainda o mais importante actor da economia mundial, apesar de eventualmente não ser a economia mais bem sucedida; quer dizer, a globalização é um fenómeno político-económico, e não puramente económico). Isto conduziu também à criação de novas formas de governação supranacional que assumiram formas de autoridade sem precedentes. De novo, contudo, tem de ser dito que estas mudanças resultam da transformação das condições da procura do lucro, que permanence o motor de todo o sistema.

Uma outra diferença reside nos "problemas centrais" que constituem a base da operação dos factores globais. Para a AGEE, estes problemas centrais são os mesmos que, como já argumentei, enquadram a agenda do estado e de todas as suas partes componentes, incluindo a educação, da sociedade capitalista: apoio ao regime de acumulação, assegurando o contexto que não inibe a sua contínua expansão e fornecendo uma base de legitimação para o sistenma como um todo. Defendi que estes três problemas não podem ser resolvidos em conjunto, tendendo antes as soluçôes para eles a ser contraditórias, e sendo essas contadições precisamente aquilo que fornece a dinâmica dos sistemas educativos (ver Dale, 1989). Na era da globalização, estes problemas tornaram-se algo que deve ser lidado tanto em nível global como em nível nacional, com a ressalva de que o lidar com eles 
Globalização e educação: demonstrando a existência de uma...

num nível terá implicações claras, directas e possivelmente contraditórias no outro nível. Ambas as formas e as prioridades relativas dos problemas centrais também acabarão por mudar.

Uma assaz útil comparação das duas abordagens nesta área pode ser encontrada no trabalho de Martha Finnemore (1996a; 1996b), que pode ser definida como uma crítica simpática da teoria que está na base da abordagem CEMC. Finnemore partilha o fundamento da abordagem na medida em que vê os sistemas conduzidos por valores assim como, mas não só, por pressões materiais, e toma a cultura global como um recurso a partir do qual os estados se inspiram e não como uma estrutura que molda as suas respostas e a selecção dos recursos. Contudo, ela vai para além da abordagem CEMC sob muitos aspectos, o que acaba por a conduzir na direcção da abordagem AGEE, tornando assim possível indicar as diferenças entre as duas abordagens de uma forma mais precisa. Ela avança com a noção da autonomia da sociedade internacional "moldada em torno de três elementos normativos fundamentais: burocracias, mercados e igualdade humana” (1996b, p. 131). Ela reconhece que estes elementos são intrinsecamente contraditórios e defende que "a contestação normativa é em grande parte aquilo que constitui precisamente a política" (ibid., p. 135). O que está aqui ausente, e o que é crucial para a diferença entre as duas posições, é que enquanto que para Finnemore, assim como aos institucionalistas mundiais, a força causal da mudança reside "no inter-subjectivo, na partilha de ideias e crenças fortes acerca do mundo, e não tanto e apenas nas condições materiais" (ibid., p. 20), a abordagem AGEE vê o capitalismo como a força causal, conduzida pela procura do lucro. Não existe uma explicação deste tipo na abordagem CEMC. Os seus proponentes não oferecem uma explicação efectiva de como é que as ideias mudam da forma como o fazem, ou por que é que essa mudança de ideias parece no mínimo não ter criado obstáculos ao desenvolvimento do capitalismo à escala mundial. Em contrapartida, a abordagem AGEE não pretende que a mudança seja conduzida apenas por factores materiais. É possível aceitar que as ideias e as crenças mudam numa base sobre a qual o capitalismo é capaz de prosperar nas mais diferenciadas culturas normativas. Faz isso sob formas muito diferentes de estado e de governo, sob muitos e diferentes regimes religiosos, sob formas de família muito diferentes. A sua selecção de mecanismos para estas instituições pode ser vista de forma bastante útil como sendo essencialmente exclusiva, mais 
do que inclusiva. Portanto, "a política mundial" retém, como "membros de pleno direito", regimes perversos e repressivos no sentido de antecipar a possibilidade da sua substituição por regimes menos dóceis à expansão da economia global; e os poderosos estados individuais estão preparados para fazer vista grossa dos abusos sobre os direiots humanos se a chamada de atenção para eles puder eventualmente fazer perder mercados e lucros. Este tipo de acções pode seguramente ser mais adequadamente explicado através da concepção da política mundial que vê o capitalismo como o condutor do que por aquela que vê a racionalização das regras acerca do progresso, da modernidade e da igualdade humana como forças causais.

\section{Concepções de educação}

A segunda área de comparação das duas abordagens reside nas suas claramente diferentes concepções de educação. Para a AGEE, a educação, enquanto variável dependente neste processo, centra-se em três questões fundamentais: a quem é ensinado o quê, como, por quem e em que circunstâncias?; como, por quem e através de que estruturas, instituições e processos são definidas estas coisas, como é que são governadas, organizadas e geridas?; quais são as consequências sociais e individuais destas estruturas e processos?

Estas questōes centram-se nos princípios e processos da distribuição da educação formal, na definiçãao, formulaçãa, transmissão e avaliação do conhecimento escolar e em como é que estas coisas se relacionam entre si. Elas dirigem-nos no sentido de descobrir como é que aqueles processos são financiados, fornecidos e regulados e como é que este tipo de formas de governação se relacionam com concepções mais amplas de governação dentro de uma sociedade.

Somos solicitados a perguntar como é que estas estruturas e processos, que titpicamente referimos sob a designação "sistemas educativos", afectam as oportunidades de vida dos indivíduos e grupos e a totalidade das relações dos sistemas educativos com as colectividades e instituições sociais mais amplas de que fazem parte.

$\mathrm{O}$ âmbito da CEMc é muito mais restrito. O título promete de alguma forma mais do que aquilo que o projecto é capaz de dar. Há um considerável número de questôes aqui presente. Primeiro, como 
já referi, há uma tendência para assumir a validade da equação escola de massa + categorias curriculares = educação. Tal reduz os sistemas educativos ao seu mandato, àquilo que é considerado desejável que eles consigam alcançar. Ignora quer a capacidade do sistema, isto é, a exequibilidade desse mandato, e a sua governação, isto é, como é que ele é coordenado no sentido de alcançar os desejáveis e possíveis fins (sobre o conceito de mandato, capacidade e governação e sua inter-relação, ver Dale, 1998a, e Dale, no prelo). A importânica de considerar estes três componentes chave dos sistemas educativos e o exame de qualquer um deles é evidente se levarmos em conta as forças e as fraquezas do foco da CEMC em questôes relacionadas com o mandato. Esta perspectiva capacita-nos para uma melhor compreensão sobre quem é ensinado e sobre aquilo que é ensinado; não nos capacita, contudo, para compreender melhor a quem é ensinado o quê. Para compreender isto é necessário considerar as questóes ligadas à capacidade e à governação, assim como aquelas ligadas ao mandato. Vale também a pena sublinhar aqui a ausência de qualquer tentative de colocar neste ponto a relação da educação com outra característica persistente da modernidade ocidental, a desigualdade social sistemática quer no nível global, quer no nível nacional. Mesmo quando concebida no âmbito restrito da sala-de-aula, a educação inclui mais do que apenas categorias curriculares. Isto é totalmente reconhecido pelo trabalhador da CEMC, pelo menos na medida em que se reconhece que existem hiatos significativos entre aquilo que as categorias do currículo implicam e aquilo que é ensinado, embora as suas implicações não surjam como sendo totalmente reconhecidas.

Contudo, isto corresponde a limitar a crítica ao nível da prática da sala-de-aula. As categorias do currículo constituem apenas uma pequena parte da política curricular, o que, em si, é apenas um aspecto da provisão da educação nos estados-nação. Enquanto que o trabalho da abordagem CEMC não faz referências amplas ao estabelecimento da política curricular, porque a educação não se limita à prática da sala-de-aula, há mais coisas implícitas na política educativa e na governação para além da política curricular; a provisão da educação não pode ser vista isoladamente do financiamento e da regulação (ver Dale, 1997). Mais, e isto é crucial, o padrão da governação educacional permanence em grande parte sob o controlo da estado, contudo novas e cada vez mais visíveis formas de desresponsabilização estão a prefigurar-se. A educação permanece um assunto intensamente político no nível nacional, e moldado por mui- 
to mais do que debates acerca do conteúdo desejável da educação. As agendas nacionais para a educação são formadas mais no nível do regime do que no nível estrutural; as "políticas educativas", o processo de determinar o conteúdo e o processo da educação são poderosamente moldados e limitados pelas "políticas educativas", pelo processo de determinação das funções a serem desempenhadas, pela importância do consequente provimento dos seus recursos, pelo sistema educativo como parte de um quadro nacional regulador mais amplo (ver Dale, 1994; Dale \& Robertson, 1998). De uma forma muito crítica, neste contexto, todos os quadros regulatórios nacionais são agora, em maior ou menor medida, moldados e delimitados por forças supranacionais, assim como por forças político-económicas nacionais. E é por estas vias indirectas, através da influência sobre o estado e sobre o modo de regulação, que a globalização tem os seus mais óbvios e importantes efeitos sobre os sistemas educativos nacionais (ver Dale, 1998a).

Portanto, enquanto os proponentes da abordagem CEMC reconhecem totalmente o hiato na sua compreensão da implementação das categorias curriculares, não há nada nesta abordagem que os capacite para preencher esse hiato ou para mapear os seus contornos. O seu foco cognitivo e a sua teoria da agência (ambas discutidas adiante) praticamente as impedem ou de reconhecer a relevância das políticas educativas ou de oferecer uma análise das influências sobre a implementação que eles reconhecem. Isto é crucial para o meu argumento acerca da relação entre globalização e educação, dado que estes factores, que até muito recentemente eram amplamente determinados em nível nacional, estão a tornar-se crescentemente elaborados através de agendas estabelecidas pela economia política global e não como problemas localmente percebidos.

Dedicar-me-ei, de seguida, a considerar a terceira área chave da diferença entre as duas abordagens, a relação entre o global e o nacional, ou como é que a globalização afecta a educação. Dividirei a minha análise pela natureza das pretensões adiantadas, pelas concepções do estado e pelas concepções de agência e de mecanismos. Como se tornará claro, estes pontos de comparação estão estritamente ligados.

\section{A relação da globalização com a educação}

Antes de discutir as pretensôes do argumento da CEMC devo chamar a atenção para algumas reservas que os seus próprios propo- 
nentes reconhecem ou assumem como implícitas. Três delas parecem importantes de sublinhar. A primeira é muito clara. É o facto de, como dizem os autores no prefácio a School knowledge for the masses, "os nossos dados serem forçosamente limitados ou superficiais. Sabemos se uma dada política de dado país inclui uma dada categoria curricular ou não, e como e qual a saliência que é dada a essa categoria. Não sabemos o que é que essa categoria significa no país (por exemplo, o currículo, o plano de aula ou o teste), não sabemos como, ou se, a categoria é efectivamente implementada em relação a crianças de diferentes classes, etnia ou género" (Meyer et al., 1992, p. xi-xii). Esta reserva é reforçada e alargada para vários pontos do trabalho do grupo.

A segunda limitação do argumento em causa reside na falta de especificidade da linguagem na qual é com frequência veiculado. Tal ocorre particularmente em duas áreas. Uma área é o amplo leque de termos usados para descrever o objecto de estudo; em vários pontos faz-se referência às "normas", "convenções", "costumes", "padrões" de nível mundial. Um problema óbvio é que todos estes termos veiculam diferentes conotaçôes. Outra área é que cada um deles contém em si diferentes significados. Considere-se, por exemplo, "padrões”. Em algumas páginas de School knowledge for the masses encontramos referências a "padrôes mundiais", implicando aparentemente uma medida de qualidade; referências a um "padrão educacional correcto", implicando aparentemente um critério de sucesso; e aos "padróes dominantes de propriedade educacional", implicando aparentemente algum tipo de norma. É possível que, dado o âmbito do argumanto, tudo isso esteja implícito no leque de termos usados. Tal poderia ser coerente com a utilização por parte de Meyer, Boli $\&$ Thomas de seis diferentes termos para "política mundial"; eles reconhecem que, "para alguns propósitos poderá ser útil distinguir mais tecnicamente entre estas designações” (Meyer et al., 1987, p. 34), e é pelo menos defensável que este tipo de distinções poderia ser muito útil aqui no sentido de fornecer uma maior precisão à natureza das pretensões que vão sendo avançadas.

Exactamente o mesmo poderia ser sugerido relativamente à segunda área de imprecisão. Este refere-se à natureza das consequências da CEMC. Tal tem vindo a ser descrito como homologia, isomorfismo, convergência, padronização, homogeneidade, similitude. Novamente, todos estes termos significam algo diferente, e, novamente também, muitas das diferenças parecem ter repercussões no argumento. 
Esta liberdade de terminologia está associada com o terceiro conjunto de reservas implícitas, isto é, com a ambiguidade acerca do âmbito e das consequências da CEMC. Fundamentalmente, por exemplo, não é claro se aquilo que está a convergir, ou a tornar-se homólogo, é um processo, um produto ou ambos. Exemplos da forte defesa da CEMC são que "uma nova cultura ou conjunto de categorias culturais estão a ser promulgados pelas instituições de educação de massas"; que "uma abordagem fundada nas perspectivas institucional e política mundiais sugere que as estruturas educacionais e o conteúdo curricular estão institucionalizados em nível mundial"; e que "os estados são activadores de perspectivas culturais". Contra isso devem ser alinhados argumentos que mostrem que as variaçóes nacionais continuam fortes (Meyer et al., 1992, p. 168), que a cultura mundial está longe de ser homogénea (ibid., p. 82) e que a incorporação do modelo pode acontecer a um nível meramente ritual.

$\mathrm{Na}$ base das pretensãoes da CEMC encontra-se uma concepção muito ampla de "cultura mundial". Cobre todas as instituições "modernas"; é difícil ver que características da vida contemporânea escapam à sua influência. $\mathrm{O}$ alcance do conceito, que inclui dentro de si as mais urgentes e polémicas questões relativas ao currículo e à educação em geral, como as da igualdade e liberdade ou a dos benefícios individuais e nacionais, significa que todos esses debates são subsumidos no interior da cultura em vez de se apresentarem como uma alternativa. Isto poderá conduzir-nos a perguntar se um conceito que aparentemente pode explicar tudo pode de facto explicar alguma coisa. E isto significa que, por seu turno, a única explicação que a abordagem é capaz de fornecer em nível mundial daquilo que pode ser mais ou menos provável de ser ensinado em nível nacional é precisamente aquilo que é improvável de ser incluído e que cai fora da fronteira extremamente ampla da CEMc. Outro tópico chave é o do tratamento da política. A política parece desaparecer aos dois níveis. Por um lado, é reduzida efectivamente à burocracia, dado que a existência de uma cultura mundial efectiva coloca os conflitos acima dos valores. Isto relaciona-se com o segundo ponto, que também foi sublinhado por Martha Finnemore (op. cit.). Ela chama a atenção para o facto de as características centrais da cultura ocidental conterem grandes contradições entre si, como entre progresso e justiça. De facto, esta crítica parece ter sido retomada por Meyer, Boli \& Thomas (1997) quando reconhecem, num artigo por 
vezes lido como uma resposta à crítica de Finnemore, que "o desfazer (da distinção entre o compromisso formal e as políticas e práticas efectivas) é algo endémico, dado que os estados-nação são modelados a partir de uma cultura externa que não pode simplesmente ser importada no seu todo como se se tratasse de um sistema a funcionar plenamente. A cultura mundial contém muitas outras variantes de modelos dominantes, o que conduz à adopção eclética de princípios conflituantes (...), sendo os modelos de cultura mundial altamente idealizados e internamente inconsistentes" (Meyer et al., 1997, p. 154).

Enquanto que os argumentos a favor da CEMC possuem alguma plausibilidade relativamente àquilo que nos dizem acerca da natureza $\mathrm{e}$ do âmbito de uma política mundial baseada numa perspectiva ocidental, a sua contribuição no sentido de especificar os efeitos sobre a educação fica limitada a duas pistas muito gerais. Por um lado, como já referi acima, a abordagem tem de facto alguma coisa a dizer acerca de quem e sobre aquilo que é ensinado, assim como acerca de como tal é definido. $\mathrm{O}$ argumento a favor da CEMC, a partir do qual praticamente todos os estados-nação derivam as suas categorias curriculares, acaba por ser limitado no trabalho empírico feito pelos institucionalistas mundiais. Por outro lado, há algum reconhecimento de que quer os sistemas educativos nacionais diferem sistematicamente entre si, quer de que, com base nas tradições nacionais, e de uma forma considerável, a conformidade em relação à CEMC é simbólica. Contudo, se estas podem não ser questôes cruciais se o foco for a natureza e o desenvolvimento do sistema-mundo, acabam por sê-lo se se pretender saber mais alguma coisa acerca de se e como é que o sistema-mundo afecta as políticas e as práticas da educação nacional.

Num certo sentido, as pretensões das duas abordagens são muito diferentes e não se sobrepõem de todo, mas poderemos resumir as suas diferenças, de uma forma muito sintética, da seguinte forma. As pretensões da CEMC são fundamentalmente a respeito da existência e da natureza de um conjunto universal de normas, ideias e valores que independentemente de qualquer delas informam e modelam a própria natureza dos estados, assim como das suas políticas. Estão menos preocupadas em estebelecer os efeitos desse conjunto de normas etc., num dado caso particular. Isto é particularmente evidente na linguagem utilizada; é suficiente para o seu propósito geral, mas não para o mais directo objectivo. A AGEE pretende ter identificado uma mudança de paradigma, um nível 
novo e qualitativamente sem precedentes de globalização que tem mudado o papel do estado tanto nacional como internacionalmente. Esta mudança afectou directamente, mas de uma forma mais significativa, indirectamente, através do impacto da globalização sobre o estado, os sistemas e políticas educativos usando mecanismos que podem ser especificados e seguidos (ver Dale, 1998b). Finalmente, as estratégias de investigação das duas abordagens também são diferentes. A maior energia por detrás da abordagem AGEE direcciona-se no sentido de estabelecer mais claramente as ligaçóes entre as mudanças na economia mundial e as mudanças na política e na prática educativas. Para a CEMC essa energia parece orientar-se em duas direcções. Uma é a crítica sempre continuada aos modelos "tradicionais" através da demonstração da sua incapacidade para dar conta das mudanças no nível nacional utilizando as explicações de nível nacional. A outra é o projecto da instalação extensiva da estrutura teórica central num conjunto crescentemente divergente de instâncias (ver Meyer sobre o meio ambiente).

\section{A natureza do estado}

A abordagem CEMC repousa sobre uma noção de estado como uma construção central da perspectiva cultural ocidental e como meio institucional através do qual as suas mensagens são veiculadas. Embora os estados-nação possam ter diferentes níveis de influência sobre a forma da cultura mundial e diferentes níveis de capacidade para a implementar, não são vistos como actores decisivos no seu desenvolvimento contínuo. Este é sobretudo o papel da ciência, especialmente tal como é delimitada e canalizada através das organizações internacionais. O que acaba por não contemplar é o facto de que muitas organizações internacionais, e certamente as mais proeminentes e eficientes dentre elas, são elas mesmas uma criação directa dos estados. Elas não emergem da "política mundial"; pelo contrário, a política mundial, das quais são tomadas como componentes, foi construída pelos estados. Mais, foi amplamente construída pelos estados no sentido de lidar com problemas que os afectavam a todos, mas que não podiam ser resolvidos por cada um individualmente. As próprias $\mathrm{Na}$ ções Unidas, e o leque de organizaçóes que surgiram a elas ligadas, foram uma construção consciente dos estados actuando em favor do interesse colectivo dos mais poderosos entre eles (e que poderia não 
ser de todo do interesse de todos). Tornou-se então a base para a atribuição do estatuto de estado enquanto meio de assegurar a perpetuação desse colectivo num mundo volátil. Vemos algo semelhante actualmente a acontecer à medida que os estados voluntariamente cedem aspectos significativos da sua soberania em favor de organizações internacionais face à premência de problemas de teor essencialmente económico que individualmente não criaram e aos quais não podem responder em termos individuais. Esta transformação, que é vulgarmente designada pela expressão criada por James Rosenau "governação sem governo", representa uma alteração qualitativa na natureza das relaçóes entre os estados e as forças supranacionais, o que é muito diferente da concepção CEMC da política mundial baseada em Organizações Internacionais Não-Governamentais (OING) (ver Rosenau, 1994). Esta última é vista como sendo conduzida por uma racionalidade técnica autónoma, auto-propulsora; a primeira é vista como sendo veiculada pelos interesses dos estados poderosos que acabam por reter a sua dominação quando esta é ameaçada por forças que eles não podem controlar. É importante, também, não menosprezar o facto de que, apesar de não serem criação directa dos estados, as OING necessariamente repousam na, no mínimo, aprovação tácita das suas actividades. Mais ainda, Boli \& Thomas (1997) pensam que cerca de $60 \%$ das OING se concentram na racionalização económica ou técnica de que dificilmente seriam promovidas a um nível mundial se tal acontecesse contra os interesses dos mais poderosos estados, que definem os padrões. De facto, poder-se-ia até argumentar que a sua promulgação através dos auspícios das OING poderá ser extremamente valiosa a estes últimos, dado que legitimam a sua origem e os interesses que veiculam.

Temos também que reconhecer que outra parte das respostas dos estados à modificação das pressões económicas e políticas globais tem ido no sentido de se reformarem a elas próprias em diferentes aspectos (ver Dale \& Robertson, 1997). Em particular, a educação tem sido o factor chave no forçar dos limites competitivos dos estados em relação uns aos outros, dado que na nova economia global os recursos humanos são muito menos "livres" do que outros tipos de recursos (ver, por exemplo, Reich, 1992). Muitos estados, especialmente os dos países anglófonos, tornaram-se menores porém mais fortes e remodelaram-se a si mesmos como estados "competitivos e contratuais", com uma gama restrita de actividades e uma gama de articulações instaladas para a coordenação de actividades não-centrais. Isto tem um certo número de consequências 
para a educação. Uma parte desta restruturação envolve um novo conjunto de relações dentro dos estados-nação; há aí uma distinção mais clara e mais significativa, por exemplo, entre os níveis regime, sectorial (incluindo a educação) e organizacional (ver Hollingsworth et al., 1994). Uma consequência importante destas mudanças é que não só os "quadros interpretativos" dos estados são afectados pelo processo de globalização, mas também que nem todos os efeitos globalmente iniciados serão mediados pelo estado. Isto é já evidente pelas actividades das ETN (cujo papel na criação de padróes técnicos globais é totalmente negligenciado por Boli \& Thomas), por exemplo, através da instalação de técnicas de produção particulares em nível de organização, sendo que alguns sectores de actividade nacionais são muito mais vulneráveis às forças supranacionais do que outros. Alguns sectores tornaram-se altamente globalizados, como resultado directo da integração mundial levada a cabo pelas ETN, muito mais do que como resultado de iniciativas nas OING mediadas pelo estado.

\section{Teoria da agência e o parque das organizações internacionais}

O problema principal da abordagem CEMC reside na sua teoria da agência. Tal resulta da estratégia correccional de explicação utilizada. A questão de saber como é que a hipotética padronização aconteceu não é enfocada directamente; como dizem Benavot et al., "Não temos informação sobre o processo pelo qual esta padronização categorial é feita" (op. cit., p. 59). As explicações dos dados sobre o crescimento dos sistemas educativos e da expansão das categorias curriculares com base em factores económicos e funcionais em nível nacional são explicitamente deixadas de lado. A CEMC é, portanto, inferida, levantando-se a hipótese de que a vasta maioria dos estados-nação funciona sobre ela. Mas tal não explica por que é que os estados-nação se comportam dessa forma. Não há sugestôes, por exemplo, de que haja alguma coisa no conteúdo da CEMC que possa conduzir a uma adesão mundial aos seus preceitos.

As explicações desenvolvem-se amplamente em torno da legitimação. Sob alguns aspectos a legitimação da CEMC pode parecer ser quase auto-gerada. Os estados têm sistemas educativos e categorias curriculares, porque outros estados também os têm; como diz John Boli, "a escolarização aconteceu na Suécia porque aconteceu na civilização ocidental. $\mathrm{O}$ mesmo pode ser dito de qualquer outro país euro-americano du- 
Globalização e educação: demonstrando a existência de uma...

rante este período: a escolarização aconteceu aí porque acontecia em todo o lado" (1992, p. 73). Trata-se de uma teoria da agência muito fraca que sugere que a escolarização se expandiu por osmose, ou pelo menos através de uma espontaneidade que não parece requerer qualquer explicação, sendo elaborada frequentemente através de uma ênfase no processo e conteúdo de legitimação. A CEMC legitima a adopção por parte dos estados de políticas, como as suas categorias curriculares, e, por seu turno, argumenta-se que extrai a sua legitimação da autoridade dos cientistas e especialistas que incorporam e "veiculam" a ideologia e os valores da modernidade ocidental sobre a qual se baseiam. Assim como a simples emulação do racionalismo técnico moderno pode fazer acelerar o processo de padronização, particularmente através de grupos e corpos científicos e profissionais. Mais, como sublinham Meyer \& Kamens, "a educação é algo de grande valor, mas não existe uma forma tecnicamente conhecida para a implementar o melhor possível - a situação é ideal para a operação de processos de moda, de imitação, e, assim, de difusão" (1992, p. 171).

Contudo, é no trabalho das organizações internacionais que mais perto nos encontramos de localizar uma teoria da agência; organizações como a UNESCO, a OCDE, o Banco Mundial e muitas outras, "particularmente aquelas que assumem uma pertença quase universal" (McNeely, 1995 , p. 484), são vistas como desempenhando um papel crucial enquanto veículos da mensagem da CEMC (ver especialmente McNeely \& Cha, 1994; McNeely, 1995). Para McNeely \& Cha, "os princípios, as normas, as regras e procedimentos da cultura da política mundial (...)" reflectem a influência mais significativa e universal do sistema global e operam de uma grande variedade de formas no sentido da institucionalização das ideologias, estruturas e práticas mundiais no nível do estado-nação e atribuem "uma certa eficiência causal" às organizações internacionais no que diz respeito à convergência das práticas educacionais nacionais (1994, p. 2-3). Esta pesada ênfase no papel central desempenhado pelas organizações internacionais enquanto "veículos" da CEMC acaba, contudo, por levanter a questão de saber como é que ela era "veiculada" antes da emergência da proeminência destas organizaçôes. $\mathrm{O}$ conteúdo efectivo da mensagem veiculada pelas organizaçôes internacionais baseia-se em modelos, categorias e guióes através dos quais o mundo é universalizado e, a um dado nível, unificado (mesmo que essa unidade constitua a base de conflitos posteriores). Assim, até a conformidade simbólica 
assume e reforça a força dos modelos e categorias. Isto já estava implícito na ênfase colocada na importância e centralidade da legitimação da CEMC por parte de cientistas e especialistas, mas é intrínseca à abordagem no seu todo. Isto tornou-se mais claro nos artigos mais recentes. Boli \& Thomas argumentam que "(q)uando falamos de cultura como sendo global, queremos dizer que as definições, os princípios e os objectivos são cognitivamente construídos de forma semelhante em todo o mundo (...). O centro da cultura mundial (é um grande número de Organizações Não-Governamentais que) se concentram na racionalização técnica e económica. É (...) técnico, funcional, altamente diferenciado e peculiarmente invisível (...) e estabelece padrōes, discute problemas, dissemina informação, defende pontos de vista legais, e escreve códigos de ética" (Boli \& Thomas, 1997, p. 173, 182-183). Para Meyer et al., "(o)s modelos de desenvolvimento nacional ou os direitos humanos veiculados pelas associações internacionais têm as suas raízes no conhecimento científico e legal, como as teorias e medidas do desenvolvimento económico nacional ou da igualdade social individual e económica. Da mesma forma, a difusão entre os estados-nação é pesadamente mediada por cientistas e profissionais que definem instâncias virtuosas, formulam modelos e apoiam activamente a sua adopção" (1997, p. 166). Uma característica importante destes argumentos é a sua grande semelhança com a linguagem usada sobre as organizações internacionais a que McNeely se refere e acerca das OING, e que são cruciais no trabalho de Boli \& Thomas. Esta semelhança desvela bastante acerca daquilo que é central e daquilo que é periférico na abordagem CEMC; se as questões de agência são centrais, não seria lógico não conseguir distinguir entre dois conjuntos de instituiçôes que são muito diferentes entre si em aspectos que são importantes para o seu desempenho enquanto "veículos" da CEMC.

Há aqui duas questôes importantes. Primeira, não há qualquer sugestão no sentido de que estas OING e os modelos que elas constroem e difundem sejam ou guiados por ou possuam qualquer impacto sobre a distribuição ou acessibilidade do poder quer em nível mundial, quer em nível nacional. A ênfase é apenas colocada na sua racionalidade técnica (e as OING já não são tratadas tão problematicamente como as organizações internacionais). Esta parece ser uma posição especialmente difícil de sustentar na área dos modelos ou até das medidas de desenvolvimento económico nacional. É muito claro que há modelos de desenvolvimento diferentes e competindo entre si (e igualmente tecnica- 
mente racionais), que a adopção de um em detrimento de outro é mais baseada na política do que, embora certamente também, nos fundamentos técnicos, e que essa escolha (ou imposição) de um qualquer modelo tem consequências cruciais para as populações nacionais (ver, por exemplo, Streeten, 1994; McGranahan, 1994). E esperamos provar que o mesmo se aplica precisamente ao espectro de questóes relativas aos direitos individuais e humanos.

A segunda questão é que parece que frequentemente os especialistas científicos não são meros veículos da cultura mundial, eles também fornecem a dinâmica para a mudança no seu interior. Como dizem Meyer et al., "os cientistas e os profissionais veiculam, em última instância, verdades racionais, unificadas e universais, esforçando-se bastante por evitar a imagem de um intermediário com interesses próprios no processo. A ciência enquanto autoridade é muito mais influente do que os cientistas enquanto grupo" (ibid.). Há aqui dois problemas. Um é que o tipo de autoridade universal atribuída à ciência é reclamado por muitos outros grupos que podem substanciar as suas pretensões; é interessante, por exemplo, que esta afirmação surja no parágrafo imediatamente a seguir àquele que contém o ponto acerca da autoridade científica dos modelos económicos. Mais, como este exemplo ilustra, onde as pretensões "científicas" não são apenas difíceis de substanciar, mas também concorrem entre si, a escolha entre elas é pelo menos provável que seja feita com base em critérios políticos e não em critérios técnicos, por mais articulados que este possam ser entre si. Para levar ainda mais longe o argumento, enquanto os especialistas e profissionais fazem sempre propostas baseados na "autoridade científica", o sucesso ou fracasso dessas propostas repousa não só na força da sua autoridade científica mas também no conjunto de condições políticas sob as quais elas são adiantadas. Um exemplo relevante poderia ser o de que a força das pretensões à autoridade científica de abordagens tão diferentes como a da "educação progressiva" e a dos métodos directos de instrução não mudaram significativamente nos últimos 20 anos, ao passo que o mesmo não aconteceu com o seu reconhecimento e apoio. Mais amplamente, parece que todas as pretensões acerca da importância da educação têm sido tratadas menos generosamente e de forma menos céptica durante este período; este facto tem certamente a ver pelo menos tanto com as mudanças no clima político da maior parte dos estados como com qualquer declínio da sua autoridade científica per se. 
O segundo problema está ligado precisamente a isto. Diz respeito ao facto de que a "ciência" não floresce - ou deixa de florescer - com base apenas nas suas pretensões cognitivas. Depende, também, das condições sociais que formam o contexto da sua operação. Aqui é necessário invocar duas questóes anteriormente focadas. Uma diz respeito à importância do reconhecimento não só do mandato para as actividades do estado, mas também à sua capacidade e governação. A segunda diz respeito ao poderoso papel das organizaçóes internacionais, enquanto instituições de "governação global" num período de intensa globalização, dado moldarem as acçôes dos estados individuais. Combinando estas duas perspectivas, somos conduzidos a reconhecer que as organizações internacionais não confinam as suas intervenções apenas à área dos mandatos políticos; elas também, e de uma forma crescente, tratam de questões quer de capacidade, quer de governação. A governação tornou-se no objectivo chave de organizações como a OCDE e o Banco Mundial nos anos mais recentes. O que isto significou no nível nacional foi a emergência comparativa da influência dessas actividades regulatórias do estado e um declínio compensatório na influência daqueles cujo trabalho está associado ao desenvolvimento do mandato - i.e., os cientistas e os profissionais. Isto não mina seriamente o argumento "cognitivo" para a expansão da CEMC, mas acaba por demonstrar a importância crucial das condições político-eocnómicas locais dado que não se limitam a meramente filtrar ou interpretar as mensagens da CEMC, mas também as admitem realmente, pelo menos enquanto dependem da "ciência" para as implementar. Nesta conexão, pode não ser acidental o facto de a teoria da CEMC ter sido desenvolvida quando a era da Guerra Fria/keynesiana começava a aproximar-se do seu fim, pois foi efectivamente uma era dourada para o florescimento da ciência com base no financiamento abundante por parte do governo. Não foi a esperteza ou a capacidade de persuadir dos cientistas e dos especialistas que fizeram deles as figures centrais do desenvolvimento da CEMC, mas antes as circunstâncias do tempo. Estas circunstâncias incluíam o financiamento abundante da ciência com fins militares. No campo da educação, as características principais do estado-providência desse período estavam ligadas precisamente ao facto de não haver um forte mandato para a educação, sendo esta sujeita a uma exclusiva governação centrada no estado; o controlo estatal da educação era levado a cabo através da manipulação da sua capacidade (ver Dale, 1995). 
Globalização e educação: demonstrando a existência de uma...

Estas circunstâncias estavam absolutamente maduras para a "captura profisional" da educação; e, mais uma vez, foram essas condições mais do que qualquer outra coisa que tornaram possível aos profissionais assumirem um papel liderante no desenvolvimento dos sistemas educativos.

Contra isto há algumas referências na literatura da CEMC que reconhecem que os poderes hegemónicos podem ter uma influência excessiva sobre o conteúdo das categorias curriculares ou que os sistemas educativos dos novos estados podem ser toldados por alguma forma de colonialismo. Se é claro que a natureza de qualquer currículo nacional não pode ser explicada funcional, histórica ou cientificamente, argumenta-se que a porta se abre para explicações centradas nos sistemas dos países dominantes. Isto acontece na medida em que a "legitimidade" dos estados enquanto estados "como devem ser" deriva da conformidade com a norma, e a norma neste caso são os sistemas educativos dos países dominantes. A adopção destes sistemas e das categorias curriculares associadas é um sinal das pretensões do estado-nação a ser um país "como deve ser". Tal reflecte essencialmente a base cognitiva das suas pretensóes acerca da natureza da CEMC, que é vista como se tendo expandido através da aprendizagem a partir da, e emulando a, CEMC enquanto organizações internacionais e seus legítimos peritos. Contudo, John Meyer \& David Kamens, na sua conclusão no School knowledge for the masses acabam por reconhecer que "(n)ão se trata simplesmente de uma questão de evolução mundial dos princípios naturais do estado-nação moderno" (ibid., p. 175), mas que as mudanças que aconteceram no currículo mundial tiveram as suas fontes nos centros metropolitanos dominantes, cujas características idiossincráticas desempenham um papel importante na evolução do currículo mundial.

O problema deste trabalho é que assume as organizações internacionais de uma forma não problemática; são tratadas ahistoricamente e, implicitamente, vistas como homogéneas e referentes a valores mundiais e à política mundial da mesma forma. Os seus diferentes modos de operação, as diferentes relações estruturais com os estados-nação e os seus sistemas educativos e diferentes objectivos fundamentais, já para não falar nas transformações destes, são totalmente ignorados neste trabalho. Os (diferentes) mecanismos através dos quais procuram afectar os sistemas educativos não são explorados, surgindo assim como veículos passivos em vez de intérpretes activos da, ou contributos para a, CEMC (ver Dale, 
1998b). Tal surge como especialmente surpreendente, dada a ênfase colocada na literatura "neo-institucionalista" sobre as maneiras como as formas organizacionais modelam as mensagens que veiculam.

A expressão mais extrema da versão de "tendência cognitivista e politicamente neutra" das actividades das organizaçôes internacionais encontra-se num artigo de Meyer et al. (1997). Eles argumentam que, "se um estado-nação específico não é capaz de implementar as políticas adequadas (...) as estruturas da sociedade mundial providenciarão a respectiva ajuda. Este processo opera mais através do apoio externo autorizante dos objectivos dos estados do que através da imposição autoritária dos poderes e interesses dominantes" (ibid., p. 159), e continuam afirmando que as "escolhas do estado-nação são menos proveaveis de entrar em conflito com as prescriçóes culturais mundiais do que as teorias realistas ou micro fenomenológicas poderiam fazer prever, dado que quer as escolhas do estado-nação, quer as pressōes mundiais derivam de instituições englobantes" (ibid., p. 160). A primeira metade desta citação parece surgir sob a forma de uma considerável evidência (ver parágrafo seguinte) e ser algo mais do que uma manifestação de um desejo. A segunda parte demonstra novamente os problemas associados com uma definição tão ampla e elástica de cultura mundial.

Não há efectivamente espaço para a expansão da escolarização ou das categorias curriculares, na medida em que estas são politicamente veiculadas, ou porque a sua recepção é voluntariamente imposta. Contudo, se se considerar, ainda que de forma breve, algumas das muito conhecidas estratégias e práticas dos estados poderosos e das organizações internacionais, torna-se evidente que a adesão pode ser conseguida através da pressão e da obrigatoriedade. A determinado nível essa pressão pode ser muito suave e indirecta, como no caso da expansão das políticas científicas nacionais patrocinadas pela UNESCO (ver Finnemore, 1993); aqui, o benefício da aparente conformidade simbólica foi o de os estados-nação serem tratados como "verdadeiros estados", e assim serem potencialmente beneficiários de outras formas mais directas e práticas de ajuda internacional que dependem precisamente desse estatuto. Mais directamente, no caso das categorias curriculares, o Banco Mundial tem sido muito mais do que um veículo passivo da CEMC. Tem tornado o financiamento educacional dependente da adopção de ênfases e abordagens específicas (ver Jones, 1995). Ainda mais claramente afectando a educação sur- 
Globalização e educação: demonstrando a existência de uma...

gem os programas de ajustamento impostos pelo Banco Mundial e pelo FMI que frequentemente exigem que os países alterem a ênfase que colocam na educação e especialmente na forma como se procede ao respectivo financiamento (o que, evidentemente, tem implicações enormes para quem é suposto aprender alguma coisa) (ver especialmente Pannu, 1996). O que aqui vemos é uma passagem através da qual a CEMC é expandida de uma "emulação voluntária" para um "ajustamento coercivo".

Aquilo para que estes exemplos apontam é que a exapnsão da CEMC é propulsionada mais politicamente do que cognitivamente. Tal ameaça seriamente os seus argumentos mais fundamentais, porque se o modelo mundial tem um condutor, quer esse condutor seja um ou mais estados (como é novamente reconhecido nas referências à influência dos poderes hegemónicos), quer seja função de interesses, então a hipótese da independência e da prioridade da perspectiva cultural ocidental - segundo a qual essa perspectiva modela as nações e o capitalismo e não o contrário - fica muito debilitada.

\section{Conclusão}

Já deve ser por ora claro que apesar das aparentes semelhanças entre a CEMC e a AGEE elas correspondem a projectos muito diferentes. A primeira procura essencialmente demonstrar a existência e o significado de uma hipotética cultura mundial e a segunda, mostrar como é que uma nova forma de força supranacional afecta os sistemas educativos nacionais.

Isto não significa que as duas abordagens nada tenham a oferecer uma à outra. A CEMC demonstrou a existência de um nível de recursos culturais partilhados sobre o qual a maior parte dos sistemas educativos se baseou. A AGEE teria todo o proveito em ter isso em conta ao determinar como é que os estados interpretam e respondem a uma agenda comum que esta abordagem propóe estar a ser imposta sobre os sistemas educativos. Contudo, tal reconhecimento terá de ter em conta que a forma, a substância e o estatuto dos guiōes se alteraram qualitativamente. São, por exemplo, mais restritos no seu âmbito, muito mais explícitos e frequentemente sujeitos à imposição, não passando pela adopção voluntária. Isto é crucial para compreender a diferença entre as duas abordagens. A AGEE introduz novas concep- 
ções sobre a natureza das forças globais e sobre como é que elas operam, e atribui estas transformaçōes à mudança da natureza das forças supranacionais, não estando os valores culturais universais e os guiôes imunes às forças da globalização, económica, política e cultural.

Podemos concluir, então, que o interesse da abordagem CEMC reside no facto de demonstrar a existência (embora não necessariamente a potência) de ideias e valores de nível mundial, mesmo - particularmente - quando estas não são reconhecidas. Consegue isto através de correlações que fornecem prima facie evidências do inesperado isomorfismo das categorias que encontra. Contudo, o carácter vago da ligação é sintomático do carácter incipiente de todo o argumento. $\mathrm{O}$ mesmo acontecendo, igualmente, em relação à relativa fraqueza, ou negligência, dos meios através dos quais são tratadas as questôes da agência e os mecanismos de difusão.

Em última análise, a AGEE pode explicar e ter em consideração a abordagem CEMC. Isto devido do facto de esta adoptar a posição segundo a qual o capitalismo é extremamente flexível em termos de arranjos institucionais através dos quais ele pode operar, e devido ao facto de haver uma clara afinidade entre o capitalismo e as instânicas características da hipotética cultura mundial. O contrário, contudo, já não é verdade.

Talvez a melhor forma de terminar este artigo seja considerar como é que a abordagem CEMC poderia interpretar o argumento de John Meyer segundo o qual as mudanças que ocorreram no currículo mundial tiveram as suas origens nos centros metropolitanos dominantes cujas características idiossincrásicas desempenham um papel considerável na evolução do currículo mundial. Os termos chave são "currículo mundial", centros metropolitanos dominantes" e "características idiossincrásicas". Para a AGEE, a existência de um currículo mundial tem, mais do que ser assumida, de ser demonstrada. $\mathrm{O}$ caso empírico avançado em apoio do argumento da CEMC é adequado para demonstrar que alguns aspectos dos sistemas educativos se fundam em "guiōes" comuns. Isto não justifica as pretensões de um "currículo mundial", se por isto quisermos significar que o conteúdo dos programas de todos os estados-nação é o mesmo. Tal implicaria não só um aprofundamento da investigação empírica, mas também o desenvolvimento de uma teoria sobre como (através de que instituições), e com que efeitos, o currículo foi criado, difundido e implementado. A 
Globalização e educação: demonstrando a existência de uma...

expressão "centros metropolitanos dominantes" é, sob alguns aspectos, uma forma neutra, mesmo anódina, de reconhecer diferenças de poder no sistema global. Como e por quê, e com que consequências esses poderes são dominantes? A expressão afasta-nos destas questões; novamente, o assunto surge como não sendo problemático. Finalmente, a expressão "características idiossincrásicas" também acaba por despolitizar a questão. Pode muito bem referir as políticas aos caprichos irracionais, como é efectivamente o caso, através dos quais os estados procuram defender e ampliar os seus interesses.

As consequências destas diferenças para uma compreensão de como é que a globalização afecta a educação são, penso eu, muito claras.

\section{Notas}

1. Este artigo faz parte de um grupo de três nos quais eu procuro desenvolver os vários aspectos desta abordagem; ver Dale, 1998a e 1998b.

2. A bibliografia contém uma ampla, mas de forma alguma completa, lista de referências a estudos nesta fecunda tradição.

3. Um argumento semelhante é adiantado por Rubinson \& Browne (1994).

\section{Referências bibliográficas}

BENAVOT, A. Curricular content, educational expension and economic growth. Comparative Education Reviw, 36, 1, p. 150-174, 1992.

BENAVOT, A.; CHA, Y.-K.; KAMENS, D.H.; Meyer, J.W.; WONG, S.-Y. Knowledge for the masses: world models and national curricula, 1920-1986. In: Meyer, J.W.; Kamens, D.H.; Benavot, A. (Org.). School knowledge for the masses: world models curricular categories in the twentieth century. Londres: Falmer, 1992. p. 40-62.

BOLI, J. In: Fuller, B.; Rubinson, R. (Org.). The political construction of educational expansion: the State, school expansion and economic change. Nova York: Praeger, 1992.

BOLI, J.; THOMAS, G.M. World culture in the world polity: a century of international non-governamental organization. Americam Sociological Review, 62, p. 171-190, 1997. 
CHA, Y.-K. The origins and expansion of primary school curricula, 1800-1920. In: Meyer, J.W.; Kamens, D.H.; Benavot, A. (Org.). School knowledge for the masses: world models curricular categories in the twentieth century. Londres: Falmer, 1992. p. 63-73.

COX, R.W. Approaches to world order. Cambridge: Cambridge University Press, 1996.

COX, R.W. (Org.). The new realism: perspectives on multilateralism and world order. Tóquio: United Nations University Press, 1997.

DALE, R. The new State and education policy. Milton Keynes: Open University Press, 1989.

DALE, R. New directions in education policy: neo keynesian, neo-liberal and neo-shumpeterian approaches. Comunicação apresentada na Conferência sobre política educativa organizada pela Association for Educational Research, Auckland, 1995.

DALE, R. The State and the governance of education: an analysis of the retructuring of the State-education relationship. In: HalsEY, A.H.; Lauder, H.; Brown, P.; Wells, A.S. (Org.). Education: culture, economy, society. Oxford: Oxford University Press, 1997. p. 273-282.

DALE, R. Globalisation: a new world for comparative education?. In: SchreIWER, J. (Org.). Discourse formation in comparative education. Berlim: Peter Lang, 1998a.

DALE, R. Specifying global effects on national policy: a focus on the mechanisms. Journal of Education Policy, 1998b.

DALE, R. Models of educational governance in the competitive contractual State. In: Wells, A.S. (Org.). Changing patterns of educational policy (no prelo).

DALE, R.; ROBERTSON, S. Resiting the nation, reshaping the State. In: Olssen, M.; Matthews, K. M. (Orgs.). Education policy in New Zeland. Palmerston North: Dunmore, 1997. p. 209-227.

FINNEMORE, M. International organizations as teachers of norms: UNESCO and science policy. International Organization, 47, 4, p. 565597, 1993. 
Globalização e educação: demonstrando a existência de uma...

FINNEMORE, M. Norms, culture and world politics: insights from sociology's institutionalism. International Organization, 50, 2, p. 325347, 1996a.

FINNEMORE, M. National interests in international society. Ithaca: Cornell University Press, 1996b.

FULLER, B.; RUBINSON, R. (Org.). The political construction of educational expansion: the State, school expansion and economic change. Nova York: Praeger, 1992.

GRIECO, J. Sources of variation in regional institutionalization in Western Europe, East Asia and the Americas. In: Mansfield, E.O.; Milner, H.V. (Org.). The political economy of regionalism. 1997. p.164-183.

HALL, P.; TAYLOR, R.C.R. Political science and the three new institutionalism. Political Studies, 44,4, p. 936-957, 1996.

HETTNE, B. The double mouvement: global market versus regionalism. In: Cox, R.W. (Org.). The new realism: perspectives on multilateralism and world order. Tóquio: United Nations University Press, 1997.

HETTNE, B. International political economy: understanding global disorder. Londres: Zed Press, 1995.

HOLLINGSWORTH, J.R.; SCMITTER, P.C.; STREECK, W. (Org.). Governing capitalist economies. Nova York: Oxford University Press, 1994.

HOPMAN, S. Review of "school knowledge for the masses". Journal of Curriculum Studies, 25, 5, p. 475-482, 1993.

JONES, P.W. World Bank financing of education: lending, learning and development. Londres: Routledge, 1992.

KAMENS, D.H.; BENAVOT, A. A comparative and historical analysis of mathematics and science curricula. In: MeYer, J.W.; Kamens, D.H.; Benavot, A. (Org.). School knowledge for the masses: world models curricular categories in the twentieth century. Londres: Falmer, 1992. p. 101-123.

KATZENSTEIN, P.J. Regionalism in comparative perspective. Cooperation and Conflict, 31, 2, p. 123-159, 1996. 
McGRANAHAN, D. Measures of development: research at United Nations Research Institute for Social Development. International Social Science Journal, 47, 1 (143), p. 39-59, 1995.

McNEELY, C.L. Constructing the nation-State: international organizations and prescriptive action. Westport, Conn.: Greenwood, 1995a.

McNEELY, C.L. Prescribing national educational policies: the role of international organizations. Comparative Education Review, 39, 4, p. 483507, 1995 b.

McNEELY, C.L.; CHA, Y.K. Worldwide educational convergence through international organizations: avenues for research. Education Policy Analysis Archives, 2, 14, 1994.

MEYER, J.W.; HANNAN, M.T. (Org.). National development and the world-system. Chicago: University of Chicago Press, 1979.

MEYER, J.W.; KAMENS, D.H. Conclusion: accounting for a world curriculum. In: Meyer, J.W.; Kamens, D.H.; Benavot, A. (Org.). School knowledge for the masses: world models curricular categories in the twentieth century. Londres: Falmer, 1992. p. 165-179.

MEYER, J.W.; BOLI, J.; THOMAS, G.M.; RAMIREZ, F.O. World society and the nation-State. American Journal of Sociology, 103, 1, p. 144-181, 1997.

MEYER, J.W.; KAMENS, D.H.; BENAVOT, A. (Org.). School knowledge for the masses: world models curricular categories in the twentieth century. Londres: Falmer, 1992.

MITTELMAN, J. (Org.). Globalization: critical reflections. Boulder: Lynne Reiner, 1996.

OECD. The OECD educational indicators: a framework for analysis. Paris, 1992.

PANNU, R.S. Neoliberal project of globalization: prospects for democratization of education. Alberta Journal of Educational Research, 42, 2, p. 87101, 1996.

POWELL, W.; DiMAGGIO, P.J. (Org.). The new institutionalism in organizational analysis. Chicago: University of Chicago Press, 1991. 
Globalização e educação: demonstrando a existência de uma...

RAMIREZ, F.O.; VENTRASCA, M.J. Building the institution of mass schooling: isomorphism in the modern world. In: FULLER, B.; RUBINSON, R. (Org.). The political construction of educational expansion: the State, school expansion and economic change. Nova York: Praeger, 1992. p. 47-59.

ROSENAU, J. (Org.). Governance without government. Cambridge: Cambridge University Press, 1992.

RUBINSON, R.; BROWNE, I. Education and economy. In: SMELSER, N.; Swedborg, R. (Org.). Handbook of economy sociology. Princeton: Princeton University Press, 1994, p. 581-599.

STRANG, D; CHANG, P.M.Y. The international labor organization and the welfare State: institutional effects on national welfare spending, 1960-80. International Organization, 47, 2, p. 235-262, 1993.

STREETEN, P. Human development: the debate about the index. International Social Science Journal, 47, 1 (143), p. 25-37, 1995.

THOMAS, G.M.; MEYER, J.W.; RAMIREZ, F.O.; BOLI, J. Institutitonal structure: constituting State; society and the individual. Beverly Hills: Sage, 1987. 